\title{
UNDERPERFORMANCE IN SOCIAL STUDIES IN GRADES 5-7 IN NAMIBIAN PRIMARY SCHOOLS: A CASE STUDY
}

DOI: http://dx.doi.org/10.17159/2223-0386/2017/n17a5

Arend E Carl

Department of Curriculum Studies

Faculty of Education

Stellenbosch University

aec2@sun.ac.za

Theopolina AN Negumbo

Department of Curriculum Studies

Faculty of Education

Stellenbosch University

tan.negumbo@gmail.com

\section{Abstract}

This article focuses on the challenges of learners' underperformance in Social Studies in Namibia. The study investigated the possible factors that may contribute to learners' underperformance in Social Studies in the selected schools. The following research question guided the investigation: What are the possible causes of underperformance of learners in Social Studies in Grades 5-7 at primary schools in Namibia? The aim was thus to investigate the possible factors which may contribute to learners' underperformance in Social Studies. Data were collected from selected teachers and principals via questionnaires and semi-structured interviews, lesson observations and an analysis of appropriate documents. Different data collection methods were used to assure the validity and reliability of the research through triangulation. Triangulation was used through the collection of data by means of questionnaires, interviews, observation, an analysis of relevant documents and a literature review. A number of factors that constitute obstacles and inhibit performance were identified. In addressing the challenges in the teaching and learning of Social Studies, teachers need to be empowered to address these factors and implement the curriculum effectively. Findings from the data identified a number of possible causes for the underperformance of learners and recommendations are made to address these problems.

Keywords: Assessment; Learners; Namibia; Social Studies; Teacher training; Underperformance.

\section{Introduction}

Before Namibia gained independence in 1990, the curriculum was based on what was then called the Bantu education system. In this system, History and Geography were implemented as two separate subjects. After independence was obtained in 1990, the Namibian government reformed the education system. In this new dispensation, History and Geography were now integrated at Grades 5-7 (upper primary phase) as one subject, called Social Studies. The 
National Curriculum for Basic Education (Ministry of Education, 2010:13) (MoE hereafter), with specific reference to Social Studies, intends learners to learn and understand the importance of human rights and democracy and environmental issues. Learners should also explore and come to understand the interaction between social, cultural, economic, civic and political issues. Despite the important role that Social Studies plays in learners' lives and the promotional requirements to progress to the next grade, there are some factors that influence learners' underperformance in Social Studies in Namibian schools. The question arose: What are the factors that may cause underperformance?

\section{Literature review}

There are many common challenges that face school principals in Namibia, some of which also influence learners' performance negatively. Mutorwa (2004) Makuwa (2004) and Nyambe (2015) single out serious problems in the Namibian education system, especially those related to learners' underperformance as compared to other countries. The Southern African Consortium for Monitoring Educational Quality (SACMEQ) was formed in 1991 to build the capacity of Ministries of Education of 15 member countries to monitor and evaluate the quality of their basic education systems. Botswana, Kenya, Lesotho, Swaziland, Malawi, Mozambique, Zambia, Mauritius, Namibia, Seychelles, Tanzania (Mainland), Tanzania (Zanzibar), Uganda and South Africa (Makuwa, 2005: Foreword). In comparing Namibia to these other southern African countries, the following was found: in Namibia, there are high levels of failure and school dropout, lower levels of literacy and numerical skills and poor results in tests and examinations at both primary and secondary education level (see full report by Makuwa, 2004).

This article focuses on the major challenges and possible factors that may contribute to learners' underperformance in Social Studies in Namibia. Much has already been written (see Adekunle, 2001; Aston, 2011; Dhurumjai, 2013; Etsey, 2005) about possible causes or factors that may contribute to the learners' academic underperformance in general, but not much with regard to a specific school subject. The literature review provided in this section describes possible factors that may contribute directly or indirectly to learners' underperformance in Social Studies. Some key factors that may influence learners' performance negatively were identified from the literature such as: untrained teachers who teach Social Studies; teaching and learning strategies 
of teachers; the role of motivation; a lack of parental involvement; the role of teaching and learning support materials; English as language of instruction as a possible barrier to learning, and the possible role of educational policy.

\section{Untrained and shortage of teachers}

According to the National Policy Guide for Social Studies (MoE, 2008:1), the establishment of a Social Studies policy is aimed at providing a well-organised and practically orientated programme in the teaching and management of Social Studies in schools. It further states that the policy guide aims to provide guidelines for subject managers in monitoring and supervising teaching and learning activities in schools. However, Negumbo (2016:123) found that the participating schools in her investigation do not put this policy into practice because teachers are not always appointed based on appropriate qualifications. Negumbo's research (2016:124) also revealed that inappropriately qualified and unqualified teachers were used to teach Social Studies in most of the schools that participated in this study. This state of affairs is contrary to what the policy requires and it could create certain challenges for untrained teachers because they could find it difficult to implement the Social Studies curriculum.

In general, teachers are thus expected to implement the curriculum based on skills and knowledge they gained during either their initial teacher-training phase and/or during continued in-service teacher training programmes. In support of this view, the National Curriculum for Basic Education (MoE, 2010:10-11) states that teaching emphasises the varied processes and skills (e.g. personal, social, cognitive, communication and numeracy skills, as well as skills with regard to Information and Technology) and learning experiences needed for the creation of knowledge (e.g. the ability to organise and apply new knowledge and skills or to apply existing knowledge and skills in new situations or innovative ways; evaluating and reflecting on completed processes; problem solving; working effectively, independently and in groups; increasingly taking responsibility for own learning). These varied learning processes should thus be emphasised, rather than relying predominantly on the mere transmission of knowledge by teachers. Carl (2012:193; Carl, 2005:223-228) argues that it is within the process of curriculum development where the teacher can and should become involved in creative ways. Teachers can implement the curriculum effectively provided they are effectively involved in curriculum development. Furthermore, teachers should not only receive effective initial 
teacher training in that particular subject but also in-service training to enable them to deliver the curriculum efficiently. Creative and productive teacher involvement and participation in curriculum development can bring about positive results (Carl, 2005:228).

A serious cause for concern in Namibia is that, despite having a policy in place, there are not enough teachers. The Minister of Education informed Parliament during the budget discussion of her ministry in March 2015 that the continued shortage of teachers in general would haunt the country for a long time (Shinovene, 2015:1). This state of affairs can also have a negative affect or impact on the availability of Social Studies teachers.

In a study conducted in Botswana, Jotia and Matlale (2011) found that teachers who did not undergo formal training in Social Studies were not aware of any special teaching and learning strategies to teach Social Studies. The Social Studies teachers indicated that they taught the subject because they did not have any other option or subject to teach (Jotia \& Matlale, 2011:119). This provides evidence that these teachers were neither formally trained, nor were they comfortable to teach Social Studies as they lacked a sound foundation of content knowledge. Although this study was done in Botswana, the question does arise as to whether this might also be the case in the Namibian context? The concern thus arises as to what the impact of being untrained in one's subject might have on learners' performance. If it is a negative impact, then what should be done with regard to teachers' preparation to implement the curriculum? The other concern is: if teachers are only teaching because there are no other options, will this not affect the teaching and learning process as well as the academic performance of learners? This formed part of the research done to investigate the possible reasons for the high failure rate in Social Studies in Namibia.

From the literature it is clear that the undertraining of Social Studies teachers may have a negative impact on learners' academic performance. If teachers are not adequately trained and therefore lack the basic subject knowledge and skills to teach and implement the Social Studies curriculum, they might hamper the learners' performance in this subject.

\section{Language, communication, and medium of instruction as a barrier to learning}

Effective communication and language literacy are of the utmost importance in teaching any subject. The medium of instruction is therefore an important factor to consider. Although English is not the home language of most 
Namibian learners, it became the medium of teaching and learning after Namibia gained independence in 1990. According to the language policy document of the Ministry of Basic Education, Sport and Culture (MBESC, 2003), English is the medium of instruction from Grades 4-12 in Namibia. Government implemented the decision through a language policy for schools, which states that learners should be taught in their home language from Grades 1-3, while from Grade 4 onwards, learners must receive instruction in English (MBESC, 2003:3).

The policy was developed to enable learners to be adequately proficient in English. The Namibian language policy thus stipulates that every schoolgoing child in Namibia should acquire adequate proficiency in English at primary school level so that learners can learn the curriculum content with ease (MBESC, 2003:63). Harris (2012:19) claims that one of the factors contributing to the high failure rates in Namibian schools is that learners are now required to learn the subject content through the medium of English. Namupala (2013:88) confirmed this claim by referring to the on-going high failure rate caused by learners' lack of proficiency in the language of teaching and learning.

The question is why English is only introduced in schools in Grade 4 and not in the pre-primary stage. Furthermore, if the transition from teaching through local languages to teaching in English should only start in Grade 5, one may ask whether other subjects would not be negatively affected. The concern is thus that this policy may increase learners' poor performance in subjects such as Social Studies. The point is that learners may take longer to adapt to a new language of instruction. In this respect, they may not easily understand the content of the subject and their academic performance may be influenced negatively. In support of this argument, Aston (2011:43) suggests that policy writers may need to re-evaluate the policy and reintroduce English as a compulsory medium of instruction in earlier grades, e.g. from the preprimary stage onwards. Thus, learners may gain proficiency in English earlier and hence find it easier to study other subjects. In the class and term tests as well as in the examinations learners may misinterpret the questions and provide incorrect answers because they are not proficient in the language.

Even though the Namibian education system now requires that English is not only a compulsory subject but also the medium of instruction, learners in Grades 4-12 may find it difficult to understand the content of their subjects because they are not proficient in English. The late Minister of Education, 
Abraham Iyambo, confirmed this issue as he stressed that the Ministry of Education was concerned about the on-going high failure rates caused by learners' lack of proficiency in the language of teaching and learning (Iyambo, 2011:14). The linguistics researchers, Mwinda and Van der Walt (2015:115), found that "[l] earners are able to receive information in a home/community language, but they are unable to produce the information in English." They mention that this issue is a big challenge for both teachers and learners, and they explain that learners in such a situation would not be able to produce subject content knowledge due to the lack of language proficiency.

From the literature review, it is clear that English, as the primary medium of instruction according to the Namibian curriculum, may need to be revisited to address issues of continuing high failure rates of many learners in Social Studies and other subjects. It is clear that a lack of a suitable level of proficiency in English might be one of the barriers impacting negatively on learners' performance in Social Studies in Namibian schools. In support of this view, Dhurumraj (2013) reports that the medium of instruction at schools affects learners' performance because the language barrier makes it difficult for learners to interpret questions during assessment activities.

\section{Lack of parental involvement}

In general, the lack of parental involvement in schools is a major concern with regard to the quality of education in Namibia. According to Peters (2014:23), parental involvement in the school context often requires parents to attend general and specific meetings, meet their children's teachers and be involved in school activities. Deslandes and Bertrand (2005:165) also refer to parental involvement as parents' role in the lives of their children both at home and at school. Parental involvement enables parents to monitor their children's schoolwork and classroom activities at home, thereby contributing to their children's success. Parents can support their children in their schoolwork by encouraging them, arranging for appropriate study time and space, monitoring their homework and showing an interest in their classroom activities. This means parents can volunteer to assist their children with school activities at home. They can also take an active role in the school governance and decision-making and so contribute towards ensuring that their children get a good education.

Although parents are required to be involved in their children's education, it seems this does not always occur. The literature indicates that often there is a 
lack of parental involvement in their child's school education; indeed, there is evidence that most parents are not involved in their children's academic activities. According to Frempong (2011:23), parental involvement is thought to decrease as children move from junior to senior school subjects. She further argues that some parents in Namibia stop caring about monitoring the academic progress of their children because of the perception that their children are then mature enough to do their schoolwork on their own. Mbugua, Kibet, Muthaa and Nkonke (2012:90) state that many parents and guardians did not receive any formal school education themselves and therefore they may not be able to support their children in academic matters. This implies that if parents' and guardians' educational background is not sound, it may influence their understanding of the importance of education. It may cause them to be uninterested in their children's school activities. On the other hand, one may argue that a lack of basic education should rather motivate parents to encourage and support their children to do well in school. Parents should help their children where they need assistance and uplift them to have a better future. Kandumbu (2005:67) argues that when parents are informed about what goes on in schools, they can play a more active and productive role in school activities to encourage their children to attend school, work hard and complete their homework on time. She further states that parents may also be able to encourage teachers to work hard and improve poor results. Parents' support to schools in the form of attending regular information sessions and meetings is likely to contribute to their children's academic achievement. In such meetings, parents could be given opportunities to address learners on any important issues concerning their academic work. By doing so parents may develop greater competence as they learn to make decisions and take responsibility within the school.

Parental involvement and positive parent-teacher interaction may positively influence learners' performances; therefore, the value of parental involvement cannot be over-emphasised.

\section{Lack of teaching and learning support materials}

For effective teaching and learning to take place there must be relevant and enough resources that may help teachers and learners in teaching and learning the content of the subject. There is a strong indication that sufficient teaching and learning resources will assist teachers in offering quality education in Namibia. Adekunle (2001:2) describes teaching resources as anything that can assist the teachers in promoting meaningful teaching and learning. 
Kandumbu (2005:96-97) identified a lack of teaching and learning support materials as one of the challenges that face the primary school education sector in Namibia.

\section{Promotional policy}

In the SACMEQ III report, Miranda, Amadhila, Dengeinge and Shikongo $(2007: 12)$ note that the promotional policy seem to have assumed that learners in Namibia would progress through Grades 1-9 without having to repeat any grade. In some cases, learners do not even achieve the basic competencies and in such instances, repeating might not be part of the solution; therefore, the Namibian education has a policy of automatic promotion. The educational policy, in particular the non-promotional policy, promotes the idea that learners should not repeat the phase or grade more than twice. This approach might lead to a high rate of failure in Social Studies, because if learners cannot cope with the subject in a lower grade, the chances are very good that they will not be able to cope with the subject in the next grade(s).

\section{Teaching and learning strategies}

There are several teaching and learning strategies that teachers can use to improve the performance of learners in Social Studies, e.g. teacher-directed methods (e.g. lecture, demonstration) and learner-centred-methods (e.g. discussion, cooperative learning, project work, role-play, experimentation) (see Jacobs, Vakalisa \& Gawe, 2004:155-213). Cawood, Strydom and Van Loggerenberg (1980:24-79) and Carl (2012:97-99) also elaborate on teaching strategies which could be considered to enhance learning, namely lectures, discussion methods, group work, self-activity and experiential learning.

In the learner-centred approach, teachers and learners play an equally active role in the learning process. Learners' learning is measured through both formal and informal forms of assessment, including group projects and classroom participation. On the other hand, in the teacher-centred approach (lecture teaching and learning approach), teachers talk more while learners are listening. In this approach, learners are viewed as empty vessels that receive information through teaching and direct instruction. Sometimes teachers write on the chalkboard and learners are requested to take notes (Negumbo, 2016:55).

According to the discussion document on learner-centred education in the Namibian context (MoE, 2003:1), learner-centredness was introduced 
in 1991 as a foundation policy for the new educational system Namibia. It replaced the teacher-centred teaching and learning approach which was the only approach which was used before Namibian independence in 1990.The document identified that there has been different understandings of what is meant by learner-centred education and how to put it into practice. This discussion document (MoE, 2003:1-2) also reported that research which was done in Namibia on learner-centred education, indicated that circulars and syllabuses, textbooks, teaching materials, assessment practices and examinations developed during the 1990, are not consistently based on the learner-centred principles as required by policy. This means that circulars and syllabuses for school are not always based on the leaner-centred principles as required. As a result, teachers may not have clear ideas on how to implement a leaner-centred approach.

In the light of this above section on teaching and learning strategies, it is thus important for teachers to learn more about the learners in their classrooms, in other words to know their learners, and to determine which strategies will best suit all the learners' needs in the classroom to enable them to optimise their learning experience. It is also important for teachers to be able to identify the criteria which might impact on the selection of appropriate teaching and learning strategies for the teaching of Social Studies. This will, however, require that teachers are welltrained and skilled in various teaching and learning strategies.

\section{Summary of literature}

It is clear from the literature that many factors could contribute to learners' underperformance in Social Studies in Namibian schools. The following factors were identified: untrained teachers who are often required to teach Social Studies; a lack of suitable and acceptable levels of proficiency in English, which is the language of instruction in Namibian schools; not enough effective parental involvement in schools; a shortage of suitable teaching and learning support material; the possible impact of a lack of skills in appropriate teaching strategies and, lastly, the impact of policy-related factors.

\section{Problem statement}

An analysis of the results of Grades 5-7 for the period 2008-2014 revealed that there is a problem of underperformance of learners in Social Studies at primary school level (Grades 5-7) in Namibia. There has been a notable underperformance as is evident from an analysis of the assessment results of Grades 5-7 from 2008- 
2014 in three primary schools in a particular Namibian school district (see Tables 1-6). These summative assessment results are based on the marks obtained in final examinations the learners wrote at the end of each year.

Table 1: Analysis of assessment results for Social Studies Grade 5 for 2008-2012

\begin{tabular}{|l|c|c|c|c|c|c|c|c|c|c|c|c|c|c|c|}
\hline Mark & \multicolumn{5}{|c|}{ A-B } & \multicolumn{5}{|c|}{ C } & \multicolumn{5}{|c|}{ D-E } \\
\hline Year & 08 & 09 & 10 & 11 & 12 & 08 & 09 & 10 & 11 & 12 & 08 & 09 & 10 & 11 & 12 \\
\hline SCHOOL X & 3 & 9 & 0 & 0 & 1 & 8 & 8 & 8 & 6 & 3 & 14 & 7 & 17 & 29 & 35 \\
\hline SCHOOL Y & 3 & 9 & 27 & 17 & 26 & 8 & 8 & 46 & 40 & 44 & 14 & 7 & 48 & 60 & 31 \\
\hline SCHOOL Z & 8 & 8 & 4 & 8 & 20 & 10 & 13 & 20 & 27 & 40 & 26 & 19 & 18 & 35 & 19 \\
\hline TOTAL & $\mathbf{1 4}$ & $\mathbf{2 6}$ & $\mathbf{3 1}$ & $\mathbf{2 5}$ & $\mathbf{4 7}$ & $\mathbf{2 6}$ & $\mathbf{2 9}$ & $\mathbf{7 3}$ & $\mathbf{7 3}$ & $\mathbf{8 7}$ & $\mathbf{5 4}$ & $\mathbf{3 3}$ & $\mathbf{8 3}$ & $\mathbf{1 2 4}$ & $\mathbf{8 5}$ \\
& $\mathbf{1 5} \%$ & $\mathbf{3 0} \%$ & $\mathbf{1 7 \%}$ & $\mathbf{1 1} \%$ & $\mathbf{2 1} \%$ & $\mathbf{2 8} \%$ & $\mathbf{3 3} \%$ & $\mathbf{3 9 \%}$ & $\mathbf{3 3} \%$ & $\mathbf{4 0 \%}$ & $\mathbf{5 7 \%}$ & $\mathbf{3 8} \%$ & $\mathbf{4 4} \%$ & $\mathbf{5 6} \%$ & $\mathbf{3 9} \%$ \\
\hline
\end{tabular}

The results of Table 1 indicate that in all the years between 2008 - 2014 learners who scored an A or B symbol, were by far in the minority. It varies from $11 \%$ to $30 \%$. Those who scored $\mathrm{C}$ symbols were an average of between $28 \%$ to $40 \%$, whilst the majority of learners (between 38\% tot $57 \%$ ) scored either a $\mathrm{D}$ or an $\mathrm{E}$ symbol.

Table 2: Analysis of assessment results for Social Studies Grade 5 for 2013-2014

\begin{tabular}{|l|c|c|c|c|c|c|}
\hline Mark & \multicolumn{2}{|c|}{ A-B } & \multicolumn{2}{c|}{ C } & \multicolumn{2}{c|}{ D-E } \\
\hline & $\mathbf{2 0 1 3}$ & $\mathbf{2 0 1 4}$ & $\mathbf{2 0 1 3}$ & $\mathbf{2 0 1 4}$ & $\mathbf{2 0 1 3}$ & $\mathbf{2 0 1 4}$ \\
\hline SCHOOL X & 16 & 10 & 13 & 23 & 45 & 39 \\
\hline SCHOOL Y & 17 & 26 & 34 & 44 & 31 & 57 \\
\hline SCHOOL Z & 14 & 38 & 35 & 19 & 22 & 39 \\
\hline TOTAL & $\mathbf{4 7}$ & $\mathbf{7 4}$ & $\mathbf{8 2}$ & $\mathbf{8 6}$ & $\mathbf{9 8}$ & $\mathbf{1 3 5}$ \\
& $(\mathbf{2 0} \%)$ & $\mathbf{( 3 6 \% )}$ & $\mathbf{( 4 3 \%}$ & $\mathbf{( 2 5 \% )}$ & $\mathbf{( 2 9 \% )}$ & $\mathbf{( 4 6 \% )}$ \\
\hline
\end{tabular}

Table 2 shows that in 2013, of the Grade 5s, only 20\% of the learners scored above average (A or B), while $36 \%$ of the leaners scored a $\mathrm{C}$ symbol (average) and $43 \%$ of the leaners scored below average (D or E). In 2014, $25 \%$ of the learners scored an A or B, 29\% obtained a C and 46\% obtained a D or E. 
Table 3: Analysis of assessment results for Social Studies Grade 6 for 2008-2012

\begin{tabular}{|c|c|c|c|c|c|c|c|c|c|c|c|c|c|c|c|}
\hline Mark & \multicolumn{5}{|c|}{ A-B } & \multicolumn{5}{|c|}{ C } & \multicolumn{5}{|c|}{ D-E } \\
\hline Year $>$ & 08 & 09 & 10 & 11 & 12 & 08 & 09 & 10 & 11 & 12 & 08 & 09 & 10 & 11 & 12 \\
\hline SCHOOL X & 0 & 2 & 0 & 0 & 3 & 4 & 6 & 7 & 8 & 15 & 19 & 10 & 9 & 8 & 4 \\
\hline SCHOOLY & 7 & 5 & 4 & 27 & 13 & 34 & 26 & 46 & 70 & 43 & 53 & 82 & 89 & 19 & 44 \\
\hline SCHOOL Z & 4 & 6 & 11 & 13 & 16 & 44 & 46 & 48 & 46 & 59 & 37 & 45 & 54 & 40 & 31 \\
\hline TOTAL & 11 & 13 & 15 & 40 & 32 & 82 & 78 & 101 & 124 & 117 & 72 & 137 & 152 & 67 & 79 \\
\hline & $7 \%$ & $6 \%$ & $6 \%$ & $17 \%$ & $14 \%$ & $50 \%$ & $34 \%$ & $38 \%$ & $54 \%$ & $31 \%$ & $44 \%$ & $60 \%$ & $57 \%$ & $29 \%$ & $35 \%$ \\
\hline
\end{tabular}

Table 3 indicates that between 2008 - 2014, only between 6 and 14\%\% of Grade 6 learners achieved an A or B symbol, between 31\% and 50\% obtained a C symbol, whilst a very high $29 \%$ to $60 \%$ obtained D and E symbols, which is below average. In 2009, 6\% of the learners obtained an A or B, 34\% achieved a $\mathrm{C}$ and $60 \%$ obtained D and E symbols. In 2010, 6\% achieved an A or B, 38\% obtained a C and 57\% obtained D and E symbols. In 2011, $17 \%$ of the learners achieved an A or B, $54 \%$ obtained a C and $29 \%$ obtained $\mathrm{D}$ and $\mathrm{E}$ symbols. Moreover, in 2012, only $14 \%$ obtained an A or B, 31\% achieved a $\mathrm{C}$ and $35 \%$ scored below average.

Table 4: Analysis of assessment results for Social Studies Grade 6 for 2013-2014

\begin{tabular}{|l|c|c|c|c|c|c|}
\hline Mark & \multicolumn{2}{|c|}{ A-B } & \multicolumn{2}{c|}{ C } & \multicolumn{2}{c|}{ D-E } \\
\hline & $\mathbf{2 0 1 3}$ & $\mathbf{2 0 1 4}$ & $\mathbf{2 0 1 3}$ & $\mathbf{2 0 1 4}$ & $\mathbf{2 0 1 3}$ & $\mathbf{2 0 1 4}$ \\
\hline SCHOOL X & 14 & 15 & 32 & 26 & 14 & 39 \\
\hline SCHOOL Y & 19 & 21 & 30 & 56 & 73 & 46 \\
\hline SCHOOL Z & 14 & 7 & 47 & 28 & 29 & 44 \\
\hline TOTAL & $\mathbf{4 7}$ & $\mathbf{4 3}$ & $\mathbf{1 0 9}$ & $\mathbf{1 1 0}$ & $\mathbf{1 1 6}$ & $\mathbf{1 2 9}$ \\
& $\mathbf{( 1 7 \% )}$ & $\mathbf{( 1 5 \% )}$ & $\mathbf{( 4 0 \% )}$ & $\mathbf{( 3 9 \% )}$ & $\mathbf{( 4 3 \% )}$ & $\mathbf{( 4 6 \% )}$ \\
\hline
\end{tabular}

Table 4 shows that the results for Social Studies for Grade 6 in 2013 were as follows: $17 \%$ of the learners achieved an $\mathrm{A}$ or $\mathrm{B}$, while $40 \%$ of the leaners obtained a C and $43 \%$ obtained a D or E symbol. In 2014, the results for Grade 6 show that only $15 \%$ obtained an A or B, while 39\% of the learners achieved a $\mathrm{C}$ and relatively high $46 \%$ of the learners obtained either a D or E symbol. 
Table 5: Analysis of assessment results for Social Studies Grade 7 for 2008-2012

\begin{tabular}{|l|c|c|c|c|c|c|c|c|c|c|c|c|c|c|c|}
\hline Mark & \multicolumn{4}{|c|}{ A-B } & \multicolumn{4}{|c|}{ C } & \multicolumn{5}{c|}{ D-E } \\
\hline Year & 08 & 09 & 10 & 11 & 12 & 08 & 09 & 10 & 11 & 12 & 08 & 09 & 10 & 11 & 12 \\
\hline SCHOOL X & 1 & 4 & 0 & 3 & 5 & 10 & 4 & 2 & 4 & 3 & 5 & 7 & 5 & 9 & 7 \\
\hline SCHOOL Y & 19 & 16 & 8 & 5 & 19 & 30 & 34 & 45 & 63 & 56 & 54 & 51 & 44 & 58 & 41 \\
\hline SCHOOL Z & 8 & 4 & 10 & 4 & 10 & 45 & 44 & 34 & 41 & 48 & 44 & 48 & 57 & 46 & 40 \\
\hline TOTAL & $\mathbf{2 8}$ & $\mathbf{2 4}$ & $\mathbf{1 8}$ & $\mathbf{1 2}$ & $\mathbf{3 4}$ & $\mathbf{8 5}$ & $\mathbf{8 2}$ & $\mathbf{8 1}$ & $\mathbf{1 0 8}$ & $\mathbf{1 0 7}$ & $\mathbf{1 0 5}$ & $\mathbf{1 0 6}$ & $\mathbf{1 0 6}$ & $\mathbf{1 1 3}$ & $\mathbf{8 8}$ \\
& $\mathbf{1 3} \%$ & $\mathbf{1 1} \%$ & $\mathbf{9 \%}$ & $\mathbf{1 5 \%}$ & $\mathbf{1 5} \%$ & $\mathbf{3 9} \%$ & $\mathbf{5 0} \%$ & $\mathbf{3 9} \%$ & $\mathbf{4 6} \%$ & $\mathbf{4 7 \%}$ & $\mathbf{4 8} \%$ & $\mathbf{4 8} \%$ & $\mathbf{5 2} \%$ & $\mathbf{4 9 \%}$ & $\mathbf{3 8} \%$ \\
\hline
\end{tabular}

Table 5 shows that in 2008, only $13 \%$ of Grade 7 learners managed to obtain an A or B symbol, 39\% achieved a C and 48\% obtained either a D or E symbols in Social Studies. In 2009, 11\% of the learners obtained an A or B, $39 \%$ achieved a $\mathrm{C}$ and a relatively high $50 \%$ obtained either a D or E symbol. In 2010, only $9 \%$ obtained an A or B, 39\% achieved a C and $52 \%$ of the learners obtained D and E symbols. In 2011, the results for Grade 7 shows that $15 \%$ achieved an A or B, $46 \%$ obtained a C and 49 obtained D and E symbols. Furthermore, the analysis results of Grade 7 in 2012 indicate that $15 \%$ of the learners achieved an A or B, $47 \%$ obtained a C and $38 \%$ obtained $\mathrm{D}$ and $\mathrm{E}$ symbols.

Table 6: Analysis of assessment results for Social Studies Grade 7 for 2013-2014

\begin{tabular}{|l|c|c|c|c|c|c|}
\hline Mark & \multicolumn{2}{|c|}{ A-B } & \multicolumn{2}{c|}{ C } & \multicolumn{2}{c|}{ D-E } \\
\hline & $\mathbf{2 0 1 3}$ & $\mathbf{2 0 1 4}$ & $\mathbf{2 0 1 3}$ & $\mathbf{2 0 1 4}$ & $\mathbf{2 0 1 3}$ & $\mathbf{2 0 1 4}$ \\
\hline SCHOOL X & 13 & 11 & 24 & 25 & 21 & 50 \\
\hline SCHOOL Y & 5 & 21 & 63 & 45 & 30 & 25 \\
\hline SCHOOL Z & 13 & 23 & 30 & 25 & 23 & 39 \\
\hline TOTAL & $\mathbf{3 1}$ & $\mathbf{5 5}$ & $\mathbf{1 1 7}$ & $\mathbf{9 5}$ & $\mathbf{7 4}$ & $\mathbf{1 1 4}$ \\
& $(\mathbf{2 1} \%)$ & $\mathbf{( 3 6 \% )}$ & $\mathbf{( 4 3 \% )}$ & $\mathbf{( 1 4 \% )}$ & $\mathbf{( 5 3 \% )}$ & $\mathbf{( 3 3 \% )}$ \\
\hline
\end{tabular}

Table 2 indicates that in 2013, 21\% of the Grade 7 learners achieved an A or B symbol, whereas $36 \%$ of the learners obtained a $\mathrm{C}$ and $43 \%$ obtained a $\mathrm{D}$ or $\mathrm{E}$ symbol. In 2014 , only $14 \%$ of the learners managed to achieve $\mathrm{A}$ or $\mathrm{B}$ symbols, whereas $53 \%$ of the learners obtained a $\mathrm{C}$ symbol and 33\% learners obtained a D or E symbol. It is evident from the results that there is a strong trend of underperformance in Social Studies in this particular district.

In the analysis of the results of grades 5-7 for the period 2008-2014 in Social Studies, it is thus clear that a problem exists with regard to underperformance. The challenge is that if learners fail Social Studies at primary school level, 
they will probably lack understanding of the interaction in social, cultural, economic, civic and political spheres, and the relationship between people and environments. However, the exact causes of underperformance in Social Studies (Grades 5-7) at primary school level in Namibia are unknown. Therefore, Social Studies can be seen as an important vehicle by which to enhance learners' understanding of these different spheres.

The research sought to determine the possible factors that play a role in the underperformance of Grades 5-7 learners in Social Studies in three selected schools in a particular Namibian school district.

\section{Research question and research aims}

The following research question guided this investigation: What are the possible causes of underperformance in Social Studies in three selected Namibian primary schools (Grades 5 and 7) of a particular school district?

\section{The aims of the study were:}

- To investigate the possible causes of learners' underperformance in Social Studies in Grades 5-7 in the three selected Namibian primary schools;

- To determine whether there are possible ways to decrease learners' poor performance in the upper primary phase in Social Studies;

- To determine the challenges of teaching and learning experienced by teachers of Social Studies, and

- To determine the efficiency of teaching and learning methods used in the teaching of Social Studies.

\section{Research design and methodology}

A research design is a master plan that provides a clear guidance on how the study is to be conducted. Both Mouton (2005) and Yin (2009) describe a research design as a blue print for conducting the research. Yin (2009:27) describes a research design as being much more than a work plan, whilst Flick (2014:112) agrees that research design concerns issues of how to plan a study. Mouton (2005:161) adds that the research design is used to describe and evaluate the performance of programs in their natural settings, focusing on the process of implementation rather than a quantifiable outcome. Merriam (1998:6) describes a research design as similar to an architectural blueprint; it is a plan for assembling, organising and integrating information. This research employed a qualitative design because the qualitative research paradigm served 
the purpose of collecting data in the form of written and spoken language, as well as through observations in the classroom (Terre Blanche, Durrheim \& Painter, 2006:47)

The research design used was a case study design within a qualitative research paradigm. This design consisted of the following broad elements or components:

- Methodology and paradigm (case study and qualitative).

- Purpose (identify possible factors contributing to learners' underperformance in Social Studies).

- Context (three selected Namibian primary schools in a particular school district).

- Research techniques (sampling, semi-structured interviews, lesson observation, analysis of policy documents).

The main purpose of the design for this research thus was to ensure that the evidence addressed the research questions. The research was designed to investigate the underperformance of learners in Social Studies at primary school level in three selected schools in a particular school district within a Namibian context. In this way, the descriptive data from the participants were gathered through semi-structured interviews, lesson observations and analysis of policy documents. Denscombe (2003:31) states that the case study offers an opportunity to explain why certain outcomes might happen. This investigation focused on identifying factors that may influence learners' poor performance in Social Studies. The researcher chose a case study in order to analyse personal and individual experiences in the field of Social Studies about the needs and the possible causes of the underperformance of learners in this field.

According to Harding (1987:2), methodology is the theory of knowledge and an interpretive framework that guides a particular research process. In other words, a framework guides the research activity. An appropriate interpretive methodology was chosen to guide the researcher in generating the data as well as in answering the research question. In this research, a case study was used to explore the experiences and challenges of the three selected principals and the five Social Studies teachers in their teaching in order to identify possible factors that may contribute to learners' underperformance in Social Studies. The methodology was shaped by the methods that were used in this study to generate data, namely a literature review, interviews, lesson observations and an analysis of policy documents. 
Ethical clearance was obtained from the specific university, and permission was given by the Namibian Education Department to conduct the research.

\section{Sampling}

Sampling is a process in research whereby a small group is identified, examined and viewed as representatives of a larger group. According to Denscombe (2003:11) the sample needs to be carefully selected if there is to be any confidence that the findings from the sample are valid, trustworthy and reliable. Flick (2014:80) argues that in qualitative research, sampling is a very important step because by sampling, researchers construct the cases they study in their research. One thus needs to select a sample from which one can learn the most. Through purposive sampling the researcher can probe the case selected as the sample. Merriam (1998:48) describes purposive sampling as based on the assumption that the researcher wants to determine, understand and gain insight. Johnson and Christensen (2004:215) define purposive sampling as a type of sampling where the researchers specify the characteristics of a population of interest.

In this research, the researcher identified three different schools from a specific school district in Namibia. Five subject teachers of Social Studies and three principals of the selected schools were approached to participate in this study as they may have an influence on learners' academic learning. These participants were also selected as they were knowledgeable and well-informed with regard to the phenomenon the researcher investigated. The researcher had easy access to the schools, teachers and principals and this aspect formed part of the purposive sampling process.

The researcher decided to choose only three schools for interviews and lesson observations because they were manageable within the proposed time allocated to complete the research report. In selecting the three schools, the following aspects were taken into consideration:

- the 2008-2014 Grades 5 -7 Social Studies analysis results;

- the distance from the researcher's place of residence (in order to make the study economically sustainable);

- the availability of resources;

- the upper primary phase, and

- $\quad$ ease of communication of the required information.

The researcher was of the view this approach would make it easier to obtain information from the selected principals and the teachers who taught Social Studies and had experience of the subject matter. 


\section{Triangulation}

In this research triangulation was used to validate the findings of the study and to making these findings trustworthy. Briggs and Coleman (2007:100) state that triangulation means "comparing many sources of evidence in order to determine the accuracy of information or phenomena". This means that triangulation is a mechanism used to ensure that data collected, as well as the findings, are valid. Triangulation is thus a process of using more than one approach towards the same phenomena to check and increase the validity of the findings.

Denzin (1987, cited in Decrop, 1999:159) identified the following four basic types of triangulation:

- Data triangulation: This method involves the use of a variety of data sources in a study.

- Method triangulation: This method refers to the use of multi-methods to study a research question.

- Investigator triangulation: This method involves different researchers interpreting the same data.

- Theoretical triangulation: This type of method involves the use of multiple perspectives to interpret a single set of data.

In order to ensure the validity of the qualitative data of this research, theoretical and method triangulation were applied in this research. Multiple data sources and multiple methods to gain more understanding of the phenomenon were utilised. The multiple methods used in this research were interviews and observations and document analysis.

\section{Semi-structured interviews}

Semi-structured interview is an approach used in qualitative research to gather relevant information the researchers are looking for. Bryman (2012, cited in Savin-Baden \& Major, 2013:356) confirms that semi-structured interviews are often used in qualitative research. A qualitative inquiry seeks to gain an understanding of and provide insight into the problem under investigation. Patton (2004:248) recommends that a rich variety of methodological combinations can be employed to illuminate an inquiry question. He refers to the semi-structured interviews format as an interview guide approach. According to this approach, the researcher follows an interview guide that consists of two set of questions to guide the interviewer when particular 
information is required from each participant (Merriam, 1998; Patton, 2002). In this study, the first part contained questions with regard to biographical information of the participants, whilst the second set of questions of the schedule contained the main questions that aimed to explore the possible factors which may contribute to learners' underperformance in Social Studies in the selected schools.

This study employed semi-structured interviews with open-ended questions. The researcher selected semi-structured interviews to collect data because this method was deemed best suited to answer the research question of this study. This type of interview allows one to have a conversation and it allows interviewees to use their own words and develop their own thoughts (Denscombe, 2007:176). Interviewees may raise their own views regarding a particular subject. This helps the participants to convey and disclose information regarded as relevant to the topic. In addition, the advantage of using this interview method is that it is a powerful tool to gain insight into educational issues through understanding the experience of individuals whose lives centre on education.

During the interviews, this semi-structural approach also allowed the interviewer to ask follow-up questions to generate even more data. Apart from the interviewing, another other technique which was used to collect data, was lesson observation.

\section{Lesson observations}

It is necessary to briefly explain why and how lesson observation was utilised. The researcher needed to observe on a first-hand basis the teachers in action whilst they were teaching the subject in order to (1) observe the approaches they were using, (2) identify possible training needs, (3) determine to what extent they were implementing the required curriculum, (4) observe learner participation and (4), observe the teaching and learning strategies utilised by teachers. An observation template was thus designed to guide and assist in focusing the lesson observation. This template or form was submitted and approved as part of the ethical clearance process, prior to undertaking the research. Field notes were taken during the lesson observation process. Permission was also obtained from all the participating teachers to sit in their classroom and observe their teaching. 


\section{Document analysis}

Savin-Baden and Major (2013:403) define documents as written, printed, visual or electronic matter that provides information or evidence or that serves as an official record. Similarly, Cohen et al. (2011:249) describe a document as a record of an event or process, as such records may be produced by individuals or groups and take many different forms. Cohen et al. (2011:250) make a distinction between primary and secondary documents. Primary documents are produced as a direct record of an event or process by a witness or subject involved in it. In this research appropriate primary documents such as the Social Studies subject guide, lessons that were prepared, assessment record sheets, as well timetables and subject files, were analysed. The researcher viewed the primary documents because they offered first-hand information. Data obtained from these documents contained information on the academic performance of the selected schools in the Karas Region, Namibia. The Social Studies syllabus, Social Studies policy, as well as copies of the scheme of work were also analysed because they are supporting learning materials of the subject.

In this research, document analysis was important, because the documents convey a message of information, for example on learners' academic performance and learners' attitudes or behaviour in the classroom during Social Studies lessons.

\section{Ethical considerations}

In this research, before conducting the interviews, observing the lessons and doing the document analysis, application letters were sent to all the appropriate authorities to obtain permission to conduct the research. Permission was asked from the Director of the Education Regional Office of the specific school district, while another letter was sent to the principals of the selected schools to grant permission for the researcher to conduct a study at their schools. Permission was granted to the researcher in writing from the specific regional office, as well as from the selected schools. Permission from all of these participants was obtained allowing the researcher to proceed with the research. Participating principals and teachers also signed a consent form and anonymity was guaranteed. The selected principals and teachers could also withdraw at any stage of the research. This study adhered to the ethical consideration procedures of the university under whose auspices the research was undertaken. An application for ethical clearance was submitted to the Research Ethics Committee of the university and permission was granted. Strict adherence was paid to the requirements when the research was done. 


\section{Interview questions}

The interview questions were divided into two sub-sections, namely interview questions for the principals and interview questions for the Social Studies teachers. These interview questions were as follows:

\section{Principals' questions}

1. What are the possible factors contributing to academic underperformance in the three selected schools?

2. What are the challenges for you in terms of learners' performance?

3. How do you motivate and support teachers in accepting the changes to the curriculum and enable them to meet the educational demands in school?

4. How often does teaching supervision occur through class visits?

\section{Teachers' questions}

1. What in-service training programme(s) did you attend with regard to teaching Social Studies?

2. How do you assist learners in learning Social Studies?

3. What teaching and learning strategies do you use in Social Studies?

4. What are the challenges of teaching and learning you have experienced in Social Studies?

5. Does educational and curriculum reform contribute to the poor academic performance of learners?

6. How do government policies affect learners' academic performance?

7. What are the problems that hinder the teaching and learning of Social Studies at upper primary school level?

\section{Profiles of participating teachers and principals}

Results indicate that out of five teachers only one had been formally trained during initial teacher training to teach Social Studies, while the rest did not have this formal training to teach the subject. The current study also revealed that not one of these teachers had attended any professional development workshops that might have enabled them to teach the subject. It can therefore be concluded that mainly untrained teachers teach Social Studies at the selected schools. If teachers are not properly trained, are not suitably equipped, and lack the basic subject knowledge and skills to teach and implement the Social Studies curriculum, their learners will probably not perform well in the subject. 
The three principals above had different profiles. They had varying management experience as principals. One principal had 26 years of teaching experience, of which 16 years were in management, the second principal had five years of management experience and the third principal six years of management experience. Two principals were male and one female. None of them teach Social Studies (only two also still teach a subject), but they all have management experience of more than five years. All three principals had done formal leadership training courses, namely two principals held a Diploma in Education, while the third principal obtained a Diploma in Business Management.

\section{Results and discussion}

On being asked, "What are the challenges for principals in terms of learners' performance?" one of the participants responded as follows:

Learners [who] are transferred from one grade to another are contributing to academic underperformance in schools because they are transferred without reach the promotional requirements. This learner may fail the next grade because he or she did not qualify to be in such grade.

Another response that revealed that the policy on the automatic transfer of learners to the next grade is a challenge at school was expressed as follows:

When it comes to the assessment policy I do not have problem but the automatic transfer, I do not support it because iflearner fails, it is a fail. There must be a reason behind in this policy but it does not help to take learners to the grade if the level is the same.

The principals were asked the following question with regard to supervision: "How often does supervision of teaching occur through class visits?" This question also helped the researcher to ascertain whether management do monitor the teaching and learning process regularly. The principals responded to these question as follows:

I do supervision once per term; and teachers do not have any problem with class visits. We compromise on the date of class visits. If you want to see the results you must monitor and supervise. [The] principal is now responsible for head of departments and the counselling teacher while head of departments are the ones who [are] responsible for teachers. So far, we did not encounter any problem with teachers' attitudes. Class visits take place every term by myself or the senior teacher; many teachers welcome class visits especially when they are well prepared.

The researcher found that all the principals only do class visits once per term. The concern is how the principals will ensure that effective teaching and learning has taken place if the class visits are only done once every term. Therefore, 
supervision, monitoring and the control of teaching must be done regularly. The participating principals were also asked how they control or monitor teaching and learning. The researcher further prompted the participants, based on responses received during the interview, whether the teaching and learning process as well as assessment is being controlled and monitored regularly. This was not a planned question included in the interview schedule but came out during the interviews. In general, supervision, monitoring and controlling are an everyday process. Therefore, principals should ensure that the teaching and learning process occurs effectively at their schools. The aim was to identify whether the management style at the school may influence learners' academic performance negatively (Negumbo, 2016:109-110).

Linked to the question above, a further question was posed to the participating principals on how they motivate their teachers. One principal responded in the following way to this question:

It is a good question you are asking, butyou know only when [the] principal is motivated, [he/she] can motivate teachers There are many ways teachers can be motivated, through teacher development programmes such as training, through peer teaching, general subject meetings and they may also be motivated to upgrade themselves. All these things depend on teachers themselves, teachers they can go for training but the output is the best.

In order for principals to be able to motivate their teachers to accept and implement any curriculum reform, the implication is that they as principals themselves need to be motivated to take ownership and responsibility of the change process. However, if principals are not motivated, they cannot motivate their teachers. The same applies to the teachers. If teachers are not motivated, they cannot in turn motivate their learners to perform well. This argument is supported by Hodgetts (1990:42), as he claims that motivation is a force that pulls a person towards a desired objective. This means that it forces people to become determined and hard-working in reaching their objectives. As can be seen from the above response, the participants were, to a certain extent, aware of the value of motivation.

Another principal responded by saying: "I used to motivate my teachers through team building and send[ing] them to the workshops when it is necessary". The third principal responded as follows: "Continuous encouragement, send[ing] them to the workshop and praise will keep the teacher motivated".

During the interviews the three school principals indicated that they motivated their teachers through training or workshops. This is a good idea, 
because training or workshops is where teachers may improve and develop their teaching skills. They may also learn how to improve their teaching strategies through training or workshops. However, the study found that out of five teachers, four indicated that they have never attended any training or workshops with regard to Social Studies. This clearly indicates that there is a contradiction between what the teachers and principals had said. There was a clear indication from the teachers' responses in this section that they are not motivated through workshops because they are never sent to workshops (Negumbo, 2016:103-104).

"The participants explained that the challenges that their schools face in terms of learners' underperformance are mainly due to the automatic transfer policy (Negumbo, 2016:112)". It is clear that one of the major challenges school leaders face is the automatic transfer policy, which has a negative impact on learners' academic performance. The participants' responses are in line with literature by Sichombe, Nambira, Tjipueja and Kapenada (2011). According to these authors, Namibian schools are faced with the problem of high grade repetition and the transferal of learners to the next grade without their achieving the basic competencies for the previous grade (Sichombe et al., 2011:25). The non-promotion transfer policy may have a negative impact on learners' performance because learners are transferred without reaching the promotion requirements. This in turn leads to a high rate of underperformance in the next grades.

Apart from the non-promotion transfer policy there are other challenges experienced by Social Studies teachers and principals when they responded to the following question: "What are the possible factors contributing to academic underperformance in schools?"

One of the participants commented as follows:

Most of the things which are contributing to the learners' poor performance at this school are lack of parents' involvement, lack of motivation, time, because most of the time children are just alone at home, their parents are always at work.

Participating teachers and principals, held the same view when one says:

One of the contributing factors really is the automatic transfer, lack of motivation, parental involvement, sometimes you may find children alone at home, their parents are working at other places. [...] Some parents [are] involved in alcoholism, so they do not pay attention to their children' education. Even the situations in our town, most of the parents are factory workers, sometimes when they go to work children are sleeping and when they come back from work they find them sleeping again. 
One of the participants agreed with this view:

What contributes toward learners' academic performance are learners that are transferred from one grade to another, lack of parent's involvement: parental involvement always remains a challenge.

Another participant had the following to say:

Parents do not like to come to school and they always excuse themselves with work. They would like to tell us that work won't allow them to come to school. This is a challenge to the school, therefore most of the time the school schedule the parents' meeting after hours.

It is clear that both the participating teachers and principals were of the view that parents were not involved in their children's education. They felt that parents were not involved in their children's education because of their work situation and alcohol abuse (Negumbo, 2016:102-103). From the analysis of the responses, it became clear that lack of parents' involvement in their children's education may have a negative influence on learners' performance. Therefore, it is suggested that proper arrangements be made so that parents may assist their children with schoolwork. They could also seek an opportunity to discuss their children's progress with the school instead of waiting for the child's report.

During the interviews with the participating teachers, the following question was also asked, "What are the challenges of teaching and learning you have experienced in Social Studies?"

Participants' responses show that a shortage of teaching and learning materials may be one of the challenges and factors that contribute to learners' underperformance. One of the participants stated:

Social Studies is ... [about] learning and understanding the subject, what usually I do is present my lesson with the project, because most of the time we do not have some materials. Most of the time I use copy and paste from the internet to present the lesson.

Another respondent remarked:

Some of the challenges are lack of materials, sometimes I have to go and make copies because learners do not have enough textbooks and it is time-consuming.

These data clearly indicate that there is a lack of teaching and learning support material at some schools. This state of affairs was verified when the researcher did the classroom lesson observations. Teaching and learning is not effective if there is a lack of support materials. Materials and appropriate resources form the foundation on which teachers base their teaching in attempting to help learners understand the subject content. Teaching and learning support 
materials also promote successful teaching and learning and help the teacher to communicate with learners more effectively (Negumbo, 2016:106).

During the interviews, some participants responded to the question, "How do government policies affect learners' academic performance?" by arguing that learners have difficulty in reading and learning in Social Studies. Some of the comments are presented below:

Learners have a problem with language; the majority do not really understand English.

So far learners whom I am teaching they cannot write English, some of the learners do not understand the content of the subject.

Sometimes learners do not understand English because most of the time they speak Afrikaans at home and at school when they are playing outside with others.

With regard to the language policy, the researcher found that some learners struggle with the content of Social Studies because of their poor proficiency in English (Negumbo, 2016:116). This is similar to the argument of Dhurumraj (2013:24), who reports that the medium of instruction at schools affects learners' performance in a subject because learners are unable to interpret questions in examinations if they do not understand questions due to the language problem.

Furthermore, the above extracts demonstrate that English as the medium of instruction is a challenge to many learners and that many lack proficiency in using the language. Owing to the language barrier, learners may find it difficult to understand the content of the subject as well as the teacher's explanation. Therefore, learners may not understand what the teacher is attempting to explain and cannot express themselves when it comes to tests or examinations. The participants' views are similar to Harris's (2012:19) argument that, learning subject content in English is one of the contributing factors to the high failure rate in Namibian schools. It is clear that a lack of a suitable level of proficiency in English might indeed be one of the barriers that have an impact on learners' performance in Social Studies in Namibian schools.

\section{Conclusion}

It is clear that the policy of automatic transfer is one of the challenges facing schools in terms of learners' poor performance. In this regard learners are transferred to the next grade even though they did do not meet the subject or grade pass requirement. Another factor that affects learners' performance is untrained teachers, in the sense that they are not trained to teach Social Studies. Untrained teachers have neither sound subject knowledge nor the skills required for implementing the Social Studies curriculum. As a result, 
learners might not perform well.

The teachers indicated that since Afrikaans is the main home language in the area where the research was undertaken, English as the language of teaching and learning is a barrier that prevents learners from fully understanding the subject content. The current language policy thus also poses a challenge. It is also evident that principals do not always monitor the teaching and learning process and that the participating teachers experience a lack of inservice training opportunities or workshops. Class visits by the participating principals to monitor teaching and learning, do not occur on a regular basis. This shows a lack of leadership and management. The results of this study highlighted the above-mentioned challenges to the learners' performance in Social Studies. This study has achieved its aim of identifying possible causes of learners' underperformance in Social Studies in selected schools in Namibia. The recommendations arising from the study are presented below.

\section{Recommendations}

This study revealed that four of the five teachers of Social Studies who participated in the research had not been trained to teach the subject. The Education Department had therefore appointed teachers who were untrained and who were required to teach a subject in which they had not specialised. It is recommended that the Education Department appoint properly trained teachers and that teachers be appointed in their area of specialisation. It is also recommended that unqualified teachers further their studies to ensure that they are competent to teach the subject. Teachers could request training by voicing their training needs to the Education Regional Office in order to engage in professional development programmes offered by educational support institutions such as the National Institute for Educational Development (NIED). Through professional development programmes, teachers may attend workshops, receive appropriate induction, be encouraged to further their studies, and become empowered to implement the curriculum of the subject they are teaching. With regard to the language policy, it is recommended that educational policy makers revisit the language policy with regard to using English as the medium of instruction. From the study it is clear that learners are struggling with the content of Social Studies because of a lack of proficiency in English. It is therefore recommended that the language policy in education be considered, which will facilitate the learning process.

It is also recommended that principals fulfil their roles as curriculum and 
instructional leaders to enhance the teaching and learning quality in schools.

It is also recommended that educational policy makers review both the promotional and the non-promotional policy, as these policies are contradictory and clearly have a negative impact on learner success. This study achieved its aim of identifying possible causes of learners' underperformance in Social Studies. Further research and the resultant recommendations could assist in progressively improving learner performance in Namibia.

\section{The road ahead}

It is clear that lobbying and more groundwork will have to be done to address the identified problems. These problems need to be addressed at government as well as at district and school level as the challenges facing the problem of underperformance, is multifaceted. In this particular context, Social Studies is clearly not achieving its goals of educating and forming learners as future responsible citizens. Collaboration between all stakeholders is required; we owe it to the children.

\section{References}

Adekunle, MO 2001. Methods and resources in teaching Social Studies. Available at http:// www.unilorin.edu.ng/journals/education/ije/dec. Accessed on 1 April 2015.

Aston, NS 2011. Impact of the Namibia educational language policy: An investigation in English as a second language across the Khomas Region between the years 2007-2010. Unpublished BEd Honours (English) dissertation, Polytechnic of Namibia, Namibia.

Briggs, A \& Coleman M 2007. Research methods in educational leadership and management. London: SAGE.

Carl, AE 2005. The "voice" of the teacher in curriculum development: A voice crying in the wilderness? South African Journal of Education, 25(4):223-228.

Carl, AE 2012. Teacher empowerment through curriculum development: Theory into Practice. $4^{\text {th }}$ Edition. Cape Town: Juta.

Cawood, J, Strydom, AH, Van Loggerenberg, NT 1980. Doeltreffende Onderwys. Goodwood: Nasou.

Cohen, L, Manion L \& Morrison, K 2000. Research methods in education, 5th Edition. New York: Routledge.

Decrop, A 1999. Triangulation in qualitative tourism research. Tourism Management, (20):157-161. 
Denscombe, M 2003. The good research guide for small-scale social projects, 2nd Edition. Philadelphia, PA: Open University Press.

Denscombe, M 2007. The good research guide for small-scale social research, 3rd Edition. Philadelphia, PA: Open University Press.

Deslandes, R \& Bertrand R 2005. Motivation of parent involvement in secondary level schooling. The Journal of Educational Research, 98(3):164-175.

Dhurumraj, T 2013. Contributory factors to poor learners in Physical Sciences in KwaZuluNatal province with special reference to schools in the Pinetown District. Unpublished Master's thesis. Pretoria: University of South Africa.

Etsey, K 2005. Causes of low academic performance of primary school pupils in the Shama Sub-metro of Shama Ahanta East Metropolitan Assembly (SAEMA) in Ghana. Paper presented at the Regional Conference on Education in West Africa, Dakar, 1-2 November.

Flick, U 2014. An introduction to qualitative research. London: SAGE Publications.

Frempong, E 2011. Factors contributing to poor performance of students in the Basic Education Certificate Examination in selected public, junior high school in Effutu Municipality. Winneba: University of Education.

Harding, S 1987. Feminism and methodology: Social science issues. Bloomington: Indiana University Press.

Harris, A 2012. Distributed leadership: Implication for the role of the principal. Journal of Management Development, 31(1):7-17.

Hodgetts, RM 1990. Management Theory Process and Practice. Orlando: Harcourt College.

Iyambo, A 2011. Minister of Education speech at the Poetics and Linguistics Association Conference. Polytechnic of Namibia. Windhoek.

Jacobs, M, Vakalisa, N \& Gawe, N 2004. Teaching-learning dynamics. $4^{\text {th }}$ Edition. Sandown: Heinemann.

Johnson, B \& Christensen, L 2004. Education research: Quantitative and qualitative approaches. Needham Heights: Allyn \& Bacon.

Jotia, L \& Matlale, J 2011. Use of instructional material in Social Studies: Impact on students' performance in primary school learning examinations in Botswana. European Journal of Educational Studies, 3(1):111-122.

Kandumbu, M 2005. Exploring education policy transformation in Namibia in terms of democratic change. Unpublished Master's thesis. Stellenbosch: Stellenbosch University. 
Makuwa, DK 2004. The SACMEQ II report: A study of the conditions of schooling and the quality of primary education in Namibia. Windhoek: Ministry of Basic Education, Sport and Culture.

MBESC (Ministry of Basic Education, Sport and Culture) 2003. The language policy for schools in Namibia. Windhoek: Government Printers.

Mbugua, ZK, Kibet K, Muthaa, GM \& Nkonke, GR 2012. Factors contributing to students' poor performance in Mathematics at Kenya Certificate of Secondary Education in Kenya: A case of Baringo Country, Kenya. American International Journal of Contemporary Research, 2(6):87-91.

Merriam, SB 1998. Qualitative research and case study applications in education. San Francisco, CA: Jossey-Bass.

Miranda, H, Amadhila, L, Dengeinge, R \& Shikongo, S 2007. SACMEQ III in Namibia: A study of the conditions of schooling and quality of education. Windhoek: Ministry of Education.

MoE (Ministry of Education) 2003. Learner-centered education in the Namibian context: Discussion document. Okahandja: NIED.

MoE (Ministry of Education) 2008. National policy guide for Social Studies. Okahandja: NIED.

MoE (Ministry of Education) 2010. The National Curriculum for Basic Education. Okahandja: NIED.

Mouton J 2005. How to succeed in your Master's and Doctoral Studies: A South African guide and resource book. Pretoria: Van Schaik.

Mutorwa, J 2004. National report on the development of education in Namibia: International Conference on Education: Geneva 2004. Windhoek: Ministry of Basic and Culture Republic of Namibia.

Mwinda, N \& Van der Walt C 2015. From 'English only' to translanguaging strategies: Exploring possibilities. Per Linguam, 31(3):100-118.

Namupala, S 2013. Factors that contribute to poor performance among Grade 10 learners in Onamutai circuit, Oshana region in Namibia. Unpublished Master's in Education thesis. Windhoek: University of Namibia.

Negumbo, TAN 2016. An investigation into underperformance in Social Studies Grade 5-7 in selected Namibian primary schools: A case study. Unpublished Master's thesis. Stellenbosch: Stellenbosch University.

Nyambe, TN 2015. Primary teachers' experiences of implementing assessment policy in Social Studies in the Okavango Region of Namibia. Unpublished Master's thesis. Stellenbosch: Stellenbosch University. 
Patton, MQ 2002. Qualitative research and evaluation methods, 2nd Edition. London: Sage Publication.

Patton, MQ 2004. Qualitative Research and Evaluation Methods, 3rd Edition. London: Sage Publication.

Peters L 2014. Somali's parents' educational support of their primary school children. Unpublished Master's thesis. Stellenbosch: Stellenbosch University.

Savin-Baden, M \& Major, CH 2013. Qualitative Research: The essential guide to theory and practice: London: Routledge.

Shinovene, I 2015 Minister probes college mergers as Alweendo calls for higher entry points: The Namibian, 7 May 2015:1.

Sichombe, B, Nambira G, Tjipueja G \& Kapenada, L 2011. Evaluation of promotional policy requirements in Namibia, No. 4 . Okahandja: NIED.

Terre Blanche, M, Durrheim, K \& Painter, D 2006: Research in practice, 2. Cape Town: UCT Press. Yin, KR 2009. Case Study Research: Design and Methods, 4. Thousand Oaks: SAGE Publication. 